2016-07-11

\title{
Student perceptions of a spiral
}

\section{curriculum}

\author{
Coelho, Catherine
}

http://hdl.handle.net/10026.1/5224

10.1111/eje. 12156

European Journal of Dental Education

Wiley

All content in PEARL is protected by copyright law. Author manuscripts are made available in accordance with publisher policies. Please cite only the published version using the details provided on the item record or document. In the absence of an open licence (e.g. Creative Commons), permissions for further reuse of content should be sought from the publisher or author. 


\title{
Student perceptions of a spiral curriculum
}

\author{
C. S. Coelho and D. R. Moles \\ Peninsula School of Dentistry, University of Plymouth, Plymouth, UK
}

keywords

spiral curriculum; students perceptions; learning.

\author{
Correspondence \\ Catherine S. Coelho \\ Peninsula School of Dentistry \\ University of Plymouth \\ John Bull Building \\ Research Way \\ Plymouth PL6 8 BU, UK \\ Tel: +44 01752586808 \\ Fax: +4401752517842 \\ e-mail: cathy.coelho@plymouth.ac.uk
}

Accepted: 8 May 2015

doi: 10.1111/eje.12156

\begin{abstract}
Aim: The aim of this study was evaluation of constructive alignment of student perceptions to a spiral curriculum, as a pre-requisite to successful learning.

Method: A survey was undertaken to evaluate student thoughts and experiences of a spiral curriculum, by participation in an anonymous voluntary questionnaire. Students were asked to rate their thoughts on their understanding, perceived benefit of and confusion with their spiral curriculum at the current time and retrospectively during previous years, and to answer free-text questions on the impact, effects on learning and future suggestions for their spiral curriculum.
\end{abstract}

Results: Sixty (86\%) students completed the questionnaire. Understanding the spiral curriculum worked enhanced with time, with the benefit of the spiral curriculum being felt more conclusively in the latter years, and the majority of students not being confused by the spiral curriculum. Those students who were most confused by the spiral curriculum were the ones who were least likely to appreciate its benefits. The opportunity for consolidation of previously visited knowledge was a perceived predominant advantage, with re-visitation of topics helping to deepen understanding and learning. Clarity on the depth of knowledge at each stage prevents information overload. A spiral curriculum must spiral and not be a repetition of previously delivered topics.

Conclusions: This study provided insights into students' perceptions of an integrated spiral curriculum, and whilst predominantly positive, there are challenges to enhance the student experience. The spiral curriculum provides an opportunity to revisit and consolidate learning to the apparent benefit of the student.

\section{Introduction}

In the quest for high-quality learning in medical education, constructive alignment of student perceptions to curricula is a fundamental prerequisite for successful approaches to learning (1-3). 'A curriculum is all the planned experiences to which the learner is exposed in order to achieve the learning goals' (4) and has, in its roundest sense, four components: the content, the teaching and learning strategy, assessment procedure and evaluation process (5), and this study focuses on the student perceptions of the teaching and learning strategy: the 'how' of curriculum design.

To realise learning goals, effective learning needs to occur and educational theories, tested empirically in the 20th century and evidenced in the literature, show that effective adult learning takes place when there is a cycle of experience, reflection, thinking and planning (6), where there is deep learning for understanding, rather than surface learning for assessment (rote learning) $(7,8)$ and where what learners already know is assimilated into new learning $(9,10)$. From these pedagogical perspectives, the spiral curriculum evolved, with horizontal and vertical integration of topics (11-13).

Horizontal integration involves topics of increasing complexity being covered throughout a year and vertical integration of topics allows students to revisit topics learnt in previous years to deepen and widen that knowledge (14). So all topics in a curriculum are revisited more than once during a course, with increasing complexity or difficulty, until full understanding or competence is achieved. Furthermore, the recommendations from the 2007 Global Conference on Dental Education stating 
that one of the several essential components of an ideal curriculum should be 'horizontal and vertical integration of subjects', that is a spiral curriculum, give credence to these philosophies (15).

Moreover, the spiral curriculum has been substantiated as an motivational tool to enhance student learning, as it activates prior knowledge, initiates interest and reinforces learning (16). And an opportunity to implement these exemplars was taken at Peninsula Dental School (PDS), opened in 2007, by designing a visionary and innovative spiral curriculum from scratch, unbound by faculty imperatives or personality directives. An integrated learning environment, with problem-based case scenarios at the very heart of the curriculum delivery, is used, with all learning centred around different case scenarios of increasing horizontal and vertical complexity, and where all other learning platforms, such as e-learning, plenary lectures, workshops, the Simulated Dental Learning Environment, Life Science resources and patient clinics, are timed and delivered to support the learning objectives of each individual case scenario (17) and where 'each time a student revisits a topic s/he identifies prior knowledge and adds complexity with new concepts, knowledge or skill in an iterative process' (18). PDS has a 4-year programme, where during the first three years of the programme, patient-based case scenarios with increasing intricacy are studied, with learning objectives mapped to each module and the General Dental Council's document 'Preparing for practice: learning outcomes for registration' (19). In the final year of the programme, there is consolidation of all the learning outcomes undertaken in the previous 3 years (Fig. 1).

A spiral curriculum is a complicated process to implement and thought needs to be given to how the end-user, that is the learner, perceives this process. Harden notes that it is important 'not to underestimate students' potential input to the curriculum. They are important stakeholders; they can make important contributions to curriculum planning and they can be drivers for change' (20). Ali et al. (21) looked at the expectations of four cohorts of students at PDS on their academic experience and found that the high expectations from the course were met throughout all years, although information overload was an issue throughout all years.

And herein lies the problem with a spiral curriculum; where and when does a learner stop learning at a specific point without knowing when that point will be revisited, and when is the depth of learning deemed to be sufficient by the learner?

Taylor and Hamdy have postulated a multitheory model for adult learning which encompasses five stages of learning: dissonance, refinement, organisation, feedback and consolidation, and which they suggest can be used to 'structure, plan and deliver successful learning experiences' (22). The very nature of a spiral curriculum may facilitate these phases through the revisitation and amalgamation of learning, overcoming uncertainty and leading to complete understanding, although this may take several loops of the spiral to accomplish.

Kinchin et al. (23) note two structures for gaining clinical knowledge, either experiential/linear knowledge that is usually gained at the chair side, or conceptual/hierarchical knowledge gained from the didactic lecture, and argue that the value of the spiral curriculum is lost when these two structures are not

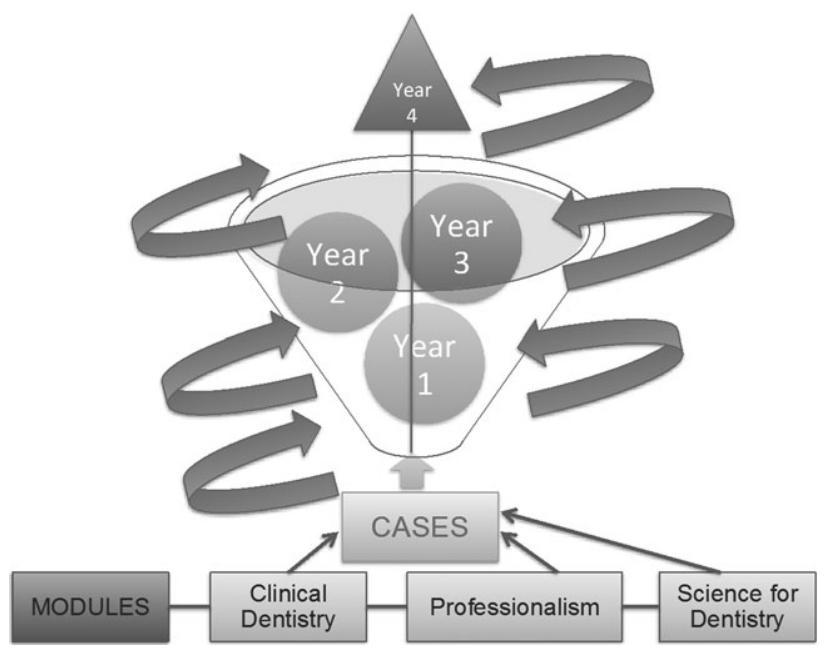

Fig. 1. Peninsula Dental School spiral curriculum.

linked, but if a spiral curriculum incorporates a qualitative dimension to student understanding, it facilitates the 'ah-ha' moment. They suggest threshold concepts are needed as a conceptual framework in dental education to address this, being gateways that need to be passed through to move learning beyond a novice level, and which are transformative, irreversible, integrative, bounded and potentially troublesome (24). Experts are seen to be able to appreciate the end result at the start of the clinical procedure and can adapt the required stages to reach it, whereas novices can only work through clearly defined stages and not depart from these stages, to reach the end result. It is suggested that identifying threshold concepts within the dental undergraduate programme is essential, using dialogue between students and faculty, not solely to identify important content to be covered, but to conceptualise and visualise thresholds to be crossed (23).

Following these enormous advances in recent years in the understanding of adult learning, it is prudent for evaluation of current curriculum design, to ensure maximal concordance between student perceptions, curriculum intents and learning stratagems. A disparity between these models can lead to underachievement and stagnation in learning (1), and the disquiets preceding the point of clarity for the individual learner, when the 'ah-ha' point is reached, maybe after several revisitations in a spiral curriculum, may be worrying and confusing.

Despite a search of the literature to gain an appreciation of this subject from the student perspective, there was a paucity of evidence found. Davis and Harden reviewed their spiral curriculum with the involvement of students and found it a robust model despite difficulty in moving from one stage to the next (25). One article was found of interest, which, despite not considering a fully integrated curriculum, studied students' perceptions of an individual specialty which was studied using a spiral curriculum. This study reported that students noted overwhelming feelings at the first loop of a spiral curriculum in anatomy, with repetition enhancing retention of knowledge (26). The literature therefore left considerable uncertainty regarding the extent to which students' perceptions are aligned to integrated spiral curricula. 
The aim of this study was to address this gap and evaluate the extent to which there is constructive alignment between the student perceptions of the spiral curriculum at PDS.

\section{Method}

A survey of all third-year students at PDS was undertaken to evaluate their thoughts and experiences of their spiral curriculum. All third-year students were invited to participate in an anonymous voluntary questionnaire during the middle of term 3. Third-year students were selected as the totality, and all the loops of the spiral curriculum are delivered by the conclusion of Year 3, that is this is the endpoint of the first round of the whole integrated spiral curriculum. This timing of the survey was chosen as a suitable point, as all the students were still in the learning phase of a spiral curriculum, but where revisitation would have occurred during the three years with possible activation of prior knowledge and reinforcement of learning.

Students were asked to rate their thoughts on their understanding, perceived benefit of and confusion with their spiral curriculum at the current time and retrospectively during previous years, using a Likert scale of $1-5$, where $1=$ totally disagree, 2 = disagree, $3=$ neutral, $4=$ agree and $5=$ totally agree. They were also given free-text space to answer questions on the impact, effects on learning and future suggestions for their spiral curriculum. This was included to gain explanations and a deeper understanding of a context-specific situation (27)

The sample group was 70 students, 68 of which were UK students and two international students, enrolled on an undergraduate dental programme, who were either graduate entry students or students from allied health professions who had demonstrated equivalence through pre-application screening.

\section{Data analysis}

The quantitative data were analysed using SPSS version 21 (Armonk, NY, USA), and inductive thematic analysis of the free text was undertaken. This involved several phases: acquaintance with the data, rereading the data, generation of initial codes, reviewing these codes, generation of concepts, searching for emerging categories, reviewing these categories and defining and naming of themes (27).

\section{Results}

Sixty students completed the questionnaire, yielding a response rate of $86 \%$. Understanding of how the spiral curriculum works in years 1, 2 and 3 changed with progression through the programme, with the median moving from 3 during Year 1, to 4 during Year 2 and then 5 in Year 3 (Fig. 2).

Understanding of how the spiral curriculum worked over the years can be said to have been enhanced with time, as $P<0.001$ for the differences between all years. The students felt the benefit of the spiral curriculum more conclusively in Year 3, with a median of 4.5, than in Year 1, with a median of 3. The data are shown in Fig. 3 and again $P<0.001$ for the differences between all the years. The majority of students in Year 3 are not confused by the spiral curriculum, where the median is 1 (Fig. 4). There was a statistically significant inverse

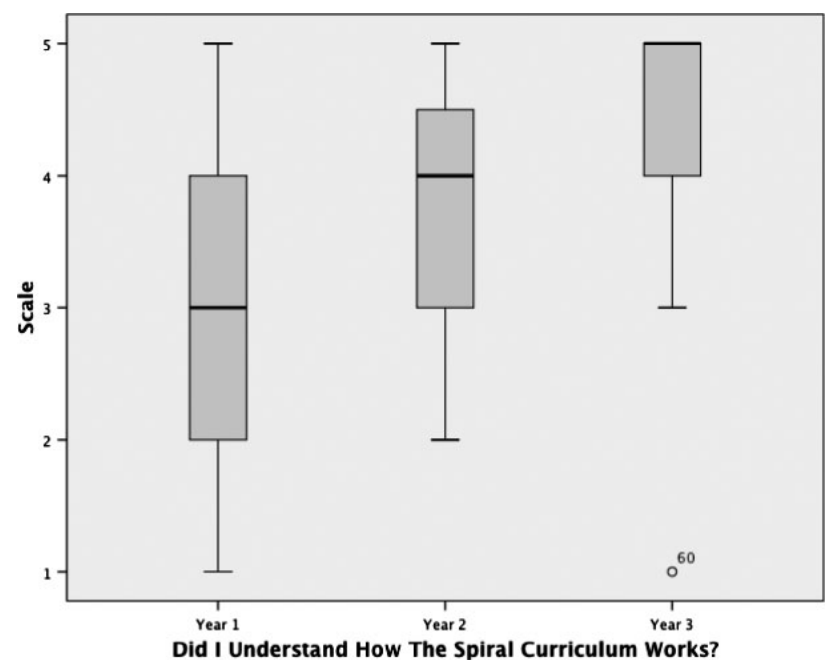

Fig. 2. Understanding of the spiral curriculum felt by the students during years 1,2 and 3 .

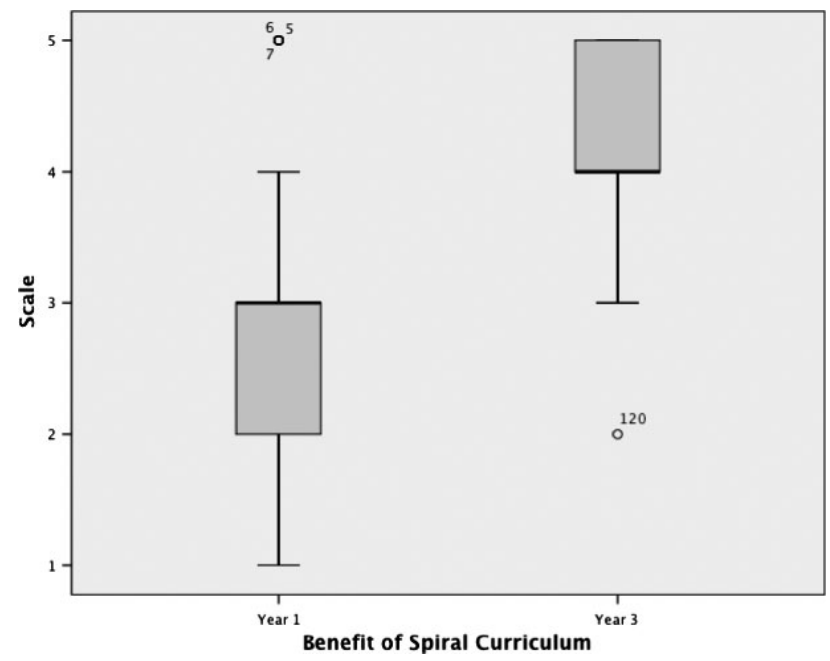

Fig. 3. Benefit of the spiral curriculum felt by the students in years 1 and 3.

correlation between students' perceptions of the benefit of the spiral curriculum in Year 3 compared to their levels of confusion (Spearman's rho $=-0.442, P<0.001$ ). This demonstrates that those students who were most confused by the spiral curriculum were the ones who were least likely to appreciate its benefits.

Of the sixty students who completed the questionnaire, forty-three made comments in the free-text space. The comments were coded for each section: the impact of the spiral curriculum, any future suggestions and the effect of the spiral curriculum. Thirty-four codes were found, although 'consolidation' was found twice, and so a total of thirty-three codes were noted. Through the iterative process, seven categories were identified (Fig. 5), with 'consolidation' occurring twice.

Overall, the students reported satisfaction with the spiral curriculum with 'cementation of knowledge' being a recurring 


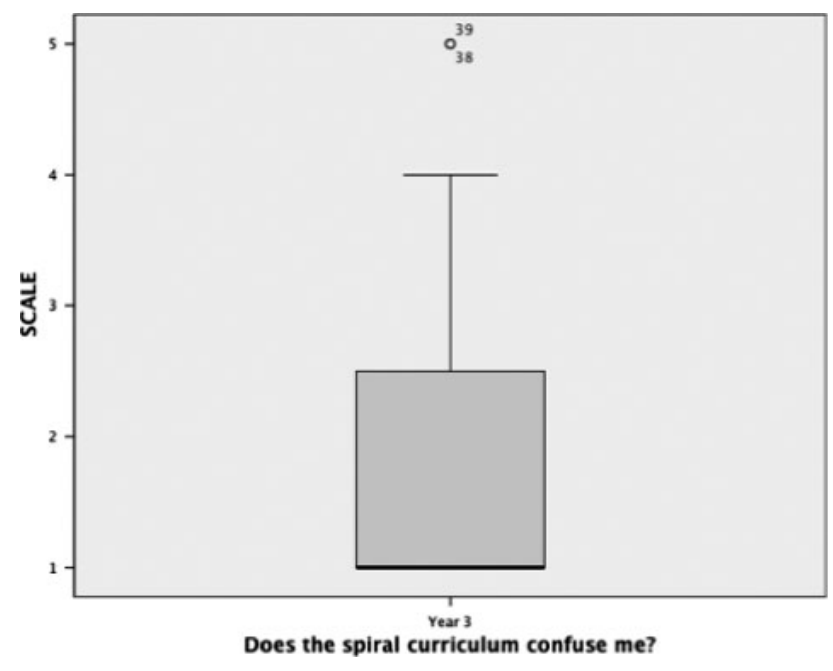

Fig. 4. Is the spiral curriculum confusing?

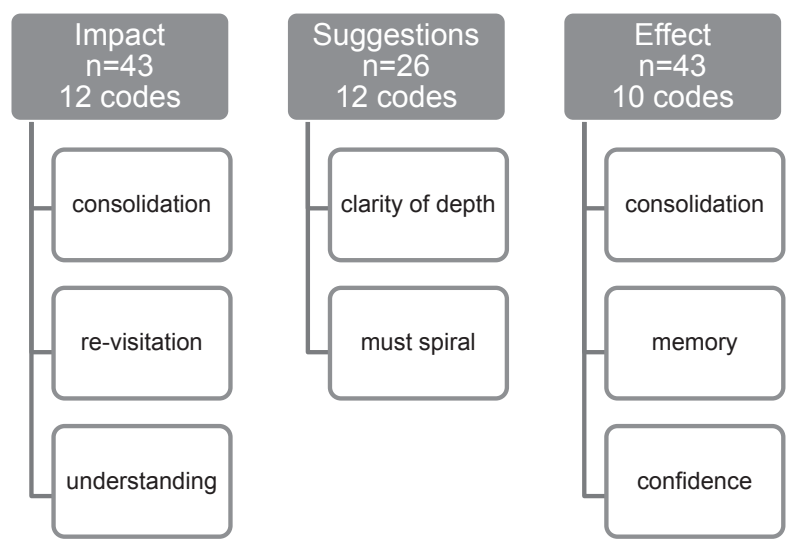

Fig. 5. Showing the categories identified following coding of the data.

positive comment. The opportunity to revisit knowledge through a variety of platforms was seen as beneficial to understanding, and there was a sense that deep understanding was occurring rather than surface learning: they 'had gone from memorising to understanding'. The opportunity to build up knowledge gradually was also felt to be advantageous, with 'consolidation' being a frequent favourable perception. Students felt their long-term memory improved as well as their confidence, and they found 'revision easier'.

The main frustrations noted by the students with a spiral curriculum was the paucity of information on exactly what knowledge was desired each year, and a confusion regarding the depth of knowledge required. One-fifth of the students had a problem with a feeling of needing to know everything about a topic when they first encountered it, and this no doubt contributed to an occasional overwhelming feeling with the amount of knowledge needed for some topics. There was also irritation at some topics not being spiralled but just revisited each year to the same depth. Not all the suggestions were corrective and some advised a perpetuation of the current state of affairs.
From this four main themes emerged from the data,

- The opportunity for consolidation of previously visited knowledge being a perceived predominant advantage, with revisitation of topics helping to deepen understanding and learning.

- Cognitive function was enhanced with improvements in memory, understanding and confidence being noted.

- Clarity on the depth of knowledge required at each stage is imperative to prevent information overload.

- A spiral curriculum must be spiral, so each new loop of the spiral must extend the learning and not be solely a repetition of previously delivered topics.

\section{Discussion}

These results indicate that students perceive a well-mapped integrated spiral curriculum to be of benefit to their learning, but that the real appreciation of a spiral curriculum is not felt until the latter years of a programme. And whilst the understanding of the theory behind implementing a spiral curriculum deepens with the passage of time, so additionally does the perceived benefit experienced by this type of curriculum. However, these perceptions were retrospective for the preceding years, and as these are remembered perceptions, they may be subject to recall bias.

Correspondingly, the primary aim of delivering high-quality learning experiences to students seems to be met by an integrated spiral curriculum, through consolidation of learning and a deep understanding and cementation of knowledge, not just at the time of assessments but continuously. This was borne out by the responses to the free-text questions where there was explicit appreciation of learning in this way. This ties in well with the hypothesis of adult learning proposed by Taylor and Hamdy (22). A period of dissonance or confusion is felt at the initial loop in a spiral curriculum, especially noted in Year 1 and corroborating the sentiments noted previously (26), where there are internal challenges of incomplete knowledge, and confusion about depth of learning. A period of refinement and organisation follows where new concepts are tested and retested during revisitation of topics in further loops of a spiral curriculum, leading to schemata that make sense. Then, an opportunity for feedback, by articulation of new knowledge with peers and teachers during other aligned learning platforms, occurs, and ultimately, culminating in a phase of consolidation during the final loop of a spiral curriculum, where knowledge is felt to be solid, comprehensive and cemented, predominantly seen in Year 3. This resonates with the lack of confusion felt by the end of Year 3.

The initial period of dissonance was felt by some but not all students in Year 1, as there was a mixed response with a full range of opinions and a median of 3 , to the initial question. Based on the work by Kolb, the resultant identification of four different learning styles by Honey and Mumford may explain this range in the dissonance felt by students (28). 'Activists' are enthusiastic about anything new and will have enjoyed the experience of dissonance. 'Theorists', needing time to integrate observations, will have felt uncomfortable with the uncertainty and untidiness of the spiral curriculum. 'Pragmatists', keen to experiment with new ideas but impatient with open-ended 
problems, may have been indifferent to the dissonance, whereas 'reflectors' pondering the experience of dissonance will have postponed making any judgment on this. However, it cannot be postulated that, whilst the dissonance receded with time, the learning style of the learner changed. It is more likely that the individual learner found a path over the 3 years, which assimilated all styles of learning as they grew in understanding of their own preferences, and had enough time to work through, in depth, the different steps in Kolb's learning cycle.

However, the anxiety felt by some students at the beginning of a course must have felt disarming if they are unable to ground themselves in the learning strategy used by a school, especially for those students coming from a previous degree culture of 'cram and dump'. It is prudent for a transparent explanation of the spiral curriculum to be given to students from the outset, although a willingness on their part to trust the benefit of this curriculum delivery is essential. Curriculum planners must inform curriculum providers the stage at which the students are throughout the different years, so that there is addition of new knowledge each year and throughout the year, without too much repetition. This was borne out by the freetext comments regarding confusion around depth of learning and the conflict between learning everything at the first exposure and being irritated with too much repeated knowledge at successive loops.

The frustration felt at the beginning of the course with a lack of clarity on depth of knowledge required was ameliorated as the years passed, and so towards the end of Year 3, the majority of students were not confused by the spiral curriculum, and this bodes well for the continuance of this type of curriculum. These findings affiliate well with the conclusions of Mattick et al. (16), where revisitation and consolidation of topics reinforce learning by enhancing understanding at a deep level, improving memory and retention of knowledge and activating prior knowledge. Nonetheless, growing levels of confidence may also account for the diminished frustration, as the curriculum moves from being science-based to clinically applicable, and the justification for knowledge acquisition, for example from science underpinning dentistry to applied clinical dental knowledge, become discernible to the learner. For example, in the case of prosthodontics dentistry, the learner may not perceive the value in understanding the underlying theory of oral musculature and tongue and saliva function, until they experience the variability in patient factors when constructing dentures and are able to adapt the science underpinning their knowledge to various clinical settings.

This furthermore affiliates well with Kinchin's view (23), in that 'consolidation' of learning perceived in Year 3 facilitates the 'ah-ha' moment, which builds confidence and sureness, and the linking of cementation of knowledge with increased clinical exposure decreases the confusion with the spiral curriculum.

The motivation for learning cannot be underestimated, and the co-construction of knowledge between novices and experts during revisiting topics in a spiral curriculum leads to socialisation into a profession, which was noted in the last century, as being crucial for adult learning (11, 29-32).

It must be acknowledged that the data collection was retrospective, as the students were commenting on the remembrance of their thoughts and feelings. A suggested recommendation to enhance the reliability of the evidence would be to study a single cohort of students over a period of years, by asking the same questions year on year. It may also be queried as to why the final year of students were not utilised, and this can be justified, as the point of delivery of the questionnaire was at the endpoint of the first round of the entire spiral curriculum, whereas the final year is used as an opportunity for amalgamation of learning. It may also be preferable to analyse 'student engagement' rather than 'student perceptions', to take into account how students engage with a spiral curriculum and strategies used for productive learning and which aligns well with directives from Higher Education Quality Assurance Agency (33).

A multiple lens look is needed to study data from all perspectives and this is challenging. The outcomes investigated here may not be optimal, and the applicability of these conclusions to different institutional settings may not be appropriate; however, the main proposal that an integrated spiral curriculum is deemed appropriate by the end-users of the exposure, that is the students, has been substantiated by this study. To capture further student insights and involve these in curriculum planning, as recommended by Harden (20), it is suggested that further appraisal of the spiral curriculum is undertaken with student focus groups, to gain clarity and perspicacity from the student perspective.

\section{Conclusion}

With the increasing emphasis on national student satisfaction scores, all institutions should be mindful of their responsibilities to enhance the student experience and empower students to engage with modern teaching and learning strategies. Quality assurance of programmes is desirable to expedite a meaningful and evidence-based understanding of the concerns faced by students. This study provided valuable insights into students' perceptions of an integrated spiral curriculum, and whilst the students' perceptions are mainly positive, there are challenges to be faced to enhance the student experience. The problems of knowing where and when to stop learning, and when the depth of learning is deemed to be sufficient by the learner, may never be answerable, but the spiral curriculum provides an opportunity to revisit and consolidate learning to the apparent benefit of the student. 'Consolidation' and 'cementation' of knowledge predominated through the thematic analysis of the benefit of a spiral curriculum, and these terms imply the cohesion of a number of items into a more comprehensible whole. The stages to travel through, from the state of liminality (on the threshold of understanding) to assimilated coalescence (acting with understanding), have been expressed many times using Miller's pyramid (34). 'Consolidation' or 'cementation' of knowledge, as the foundation of understanding, can then provide the stepping stone to competence and ultimately action, which, from the student perspective, is critical when providing clinical care to patients.

There are ongoing challenges to be met when delivering a spiral curriculum to meet the students' needs, and thought must be given to explaining the spiral curriculum during induction and throughout the course to students. Additionally, the content of a curriculum cannot be static, it must respond 
to the needs of a changing population and changes in disease patterns and equip the graduating dentist to serve the corollary of these needs, with contemporaneous knowledge, skills and attitudes. Further work is recommended to ascertain student insights into these modifications; nevertheless, this paper provides evidence to support the continuance of the spiral curriculum.

\section{References}

1 Genn JM. AMEE, Medical Education Guide No. 23 (Part 1): curriculum, environment, climate, quality and change in medical education - a unifying perspective. Med Teach 2001: 23: 279-283.

2 Lizzio A, Wilson K, Simons R. University students' perceptions of the learning environment and academic outcomes: implications for theory and practice. Stud High Educ 2002: 27: 27-52.

3 Kang I, Foster Page LA, Anderson VR, Thomson WM, Broadbent JM. Changes in students' perceptions of their dental education environment. Eur J Dent Educ 2015: 19: 122-130.

4 Rogers A. Teaching adults. Buckingham, Philadelphia: Open University Press, 1996.

5 Prideaux D. ABC of learning and teaching in medicine: curriculum design. Br Med J 2003: 326: 268-270.

6 Kolb DA. Experiential learning: experience as the source of learning and development. Englewood Cliffs, NJ: Prentice Hall, 1984.

7 Entwistle NJ, Hanley M, Ratcliffe G. Approaches to learning and levels of understanding. Br J Educ Psychol 1979: 5: 99-114.

8 Entwistle NJ, Robinson M. Personality, cognitive style and students' learning strategies. High Educ Bull 1976: 6: 23-43.

9 Freire P. Pedagogy of the oppressed. Harmondsworth: Penguin, 1972.

10 Knowles MS. Informal adult education. New York: Association Press, 1950.

11 Bruner JS. The process of education. Cambridge MA: Harvard University Press, 1960.

12 Harden RM, Stamper N. What is a spiral curriculum? Med Teach 1999: 21: 141-143.

13 Rohlin M, Peterson K, Svensater G. The Malmo model: a problembased learning curriculum in undergraduate dental education. Eur J Dent Educ 1998: 2: 103-114.

14 Harden RM. What is a spiral curriculum? Med Teach 1999: 21: $141-143$.

15 Oliver R, Kersten H, Vinkka-Puhakka H, et al. Curriculum structure: principles and strategy. Eur J Dent Educ 2008: 12(suppl): 74-84.

16 Mattick K, Knight L. High-quality learning: harder to achieve than we think? Med Educ 2007: 41: 638-644.
17 McHarg J, Kay EJ. The anatomy of a new dental curriculum. Br Dent J 2008: 204: 635-638.

18 McHarg J, Kay EJ. Designing a dental curriculum for the twentyfirst century. Br Dent J 2009: 207: 493-497.

19 General Dental Council. Preparing for practice. Dental Team Learning Outcomes for registration. 2013.

20 Harden RM. Looking back to the future: a message for a new generation of medical educators. Med Educ 2011: 45: 777-784.

21 Ali K, McHarg J, Kay E, et al. Academic environment in a newly established dental school with an enquiry-based curriculum: perceptions of students from the inaugural cohorts. Eur J Dent Educ 2012: 16: 102-109.

22 Taylor DCM, Hamdy H. Adult learning theories: implications for learning and teaching in medical education: AMEE Guide No. 83. Med Teach 2013: 35: e1561-e1572.

23 Kinchin IM, Cabot LB, Kobus M, Woolford M. Threshold concepts in dental education. Eur J Dent Educ 2011: 15: 210-215.

24 Meyer JHF, Land R. Threshold concepts and transformative ways of thinking within research into higher education in overcoming barriers to student understanding: threshold concepts and troublesome learning. London: Routledge, 2006.

25 Davis MH, Harden RM. Planning and implementing an undergraduate medical curriculum: the lessons learned. Med Teach 2003: 25: 596-608.

26 Bergman EM, de Bruin ABH, Herrler A, Verheijen IWH, Scherpbier AJ, van der Vleuten CP. Students' perceptions of anatomy across the undergraduate problem-based learning medical curriculum: a phenomenographical study. BMC Med Educ 2013: 13: 152-163.

27 Silverman D. Doing qualitative research, 4th edn. London: Sage Publications, 2013.

28 Honey P, Mumford A. Manual of learning styles. London: P. Honey, 1982.

29 Bandura A. A social learning experience. Englewood Cliffs, NJ: Prentice Hall, 1977.

30 Bleakley A. Pre-registration house officers and ward-based learning: a new "apprenticeship" model. Med Educ 2002: 36: 9-15.

31 Lave J, Wenger E. Situated learning. Legitimate peripheral participation. Cambridge: University of Cambridge Press, 1991.

32 Vygotsky. Mind in society. Cambridge, MA: Harvard University Press, 1978.

33 Coates $\mathrm{H}$. The value of student engagement for higher education quality assurance. Qual High Educ 2005: 11: 25-36.

34 Miller G. The assessment of clinical skills/competence/performance. Acad Med 1990: 65: s63-s67. 